\title{
HUBUNGAN ANTARA EFIKASI DIRI DENGAN PROBLEM FOCUSED COPING PADA MAHASISWA YANG SEDANG MENYUSUN SKRIPSI DI FAKULTAS KEGURUAN DAN ILMU PENDIDIKAN UNIVERSITAS HALU OLEO KENDARI
}

\author{
Wahiudin Pasiori ${ }^{1}$, Jamiludin ${ }^{2}$, Citra Marhan ${ }^{3}$ \\ Program Studi Psikologi \\ Fakultas Keguruan dan Ilmu Pendidikan, Universitas Halu Oleo \\ Email:wahiudin.pasiori@yahoo.com
}

\begin{abstract}
ABSTRAK
Wahiudin Pasiori (A1R1 15 032), "Hubungan Antara Efikasi Diri dengan Problem Focused Coping pada Mahasiswa yang Sedang Menyusun Skripsi di Fakultas Keguruan dan Ilmu Pendidikan Universitas Halu Oleo Kendari”. Penelitian ini bertujuan untuk menguji hubungan antara efikasi diri dan problem focused coping pada mahasiswa yang sedang menyusun skripsi. Hipotesis dalam penelitian ini adalah terdapat hubungan positif antara efikasi diri dengan problem focused coping. Responden dalam penelitian ini adalah 95 mahasiswa yang sedang menyusun skripsi di Fakultas Keguruan dan Ilmu Pendidikan Universitas Halu Oleo yang dipilih dengan teknik proportional random sampling. Pengumpulan data dilakukan menggunakan skala efikasi diri dan skala problem focused coping. Skala efikasi diri memiliki koefisien reliabilitas sebesar 0,937 dan skala problem focused coping memiliki koefisien reliabilitas sebesar 0,920 Teknik analisis data dalam penelitian ini menggunakan uji korelasi Product Moment Pearson dengan bantuan SPSS 16.0 for windows. Hasil analisis data menunjukkan bahwa hipotesis dalam penelitian ini diterima. Hal tersebut menunjukkan bahwa terdapat korelasi positif antara efikasi diri dan problem focused coping pada mahasiswa yang sedang menyusun skripsi $(\mathrm{r}=0,858, \mathrm{p}=0,000)$.
\end{abstract}

Kata Kunci: efikasi diri, problem focused coping, mahasiswa yang sedang menyusun skripsi

\section{ABSTRACT}

Wahiudin Pasiori (A1R1 15 032). "The Relationship between Self Efficacy and Problem Focused Coping among Students who are Preparing Their Thesis at Faculty of Teacher Training and Education Halu Oleo University". This research aimed to examine the relation between self efficacy and problem focused coping among students who are preparing their thesis. The hypothesis in this research was a positive relation between self efficacy and problem focused coping. Respondents in this research were 95 students who were preparing a thesis at Faculty of Teacher Training and Education Halu Oleo University that selected by using proportional random sampling technique. Data collection was done by using self efficacy scale and problem focused coping. The self efficacy scale has a reliability coefficient of 0.937 while problem focused coping scale has a reliability coefficient of 0.920. Data analysis techniques in this research using Pearson Product Moment correlation test with SPSS 16.0 for windows. The results of the data analysis showed that the hypothesis in this research was accepted. It showed that there was positive significant correlation between self efficacy and problem focused coping among students who were writing a thesis $(r=$ $0.858, p=0.000$ ).

Keywords: self efficacy, problem focused coping, students who are preparing thesis 


\section{Pendahuluan}

Pada usia remaja akhir, mahasiswa sebagai seorang pelajar memiliki tuntutan untuk dapat mengembangkan diri dengan optimal dalam berbagai masalah. Mahasiswa juga dituntut agar mampu mengambil keputusan terkait pengembangan karier, hubungan sosial, keluarga serta terkait dengan pola hidup. Menurut Suwarsi dan Handayani (2017) sebagai mahasiswa tekanan yang dihadapi akan semakin berat. Tekanantekanan tersebut berupa pencapaian prestasi akademik, hasil belajar dan pencapaian standar prestasi belajar yang semakin meningkat. Apalagi ketika mahasiswa sudah berada pada tahap akhir akademisnya, dimana mahasiswa dituntut untuk menyelesaikan tugas akhir atau skripsi.

Menurut Poerwadarminta (dalam Mastuti 2010) skripsi adalah karangan ilmiah yang diwajibkan sebagai bagian dari persyaratan pendidikan akademis. Dalam membuat skripsi, mahasiswa harus mempunyai motivasi yang baik agar skripsinya dapat diselesaikan dengan baik pula. Skripsi adalah karya tulis ilmiah akhir seorang mahasiswa dalam menyelesaikan program strata satu. Skripsi tersebut adalah bukti kemampuan akademik mahasiswa yang bersangkutan dalam penelitian yang berhubungan dengan masalah pendidikan sesuai dengan bidang studinya. Jadi mahasiswa yang sedang menyusun skripsi adalah individu yang sedang menyusun karya ilmiah akhir dengan tujuan untuk menyelesaikan program strata satu.

Proses menyelesaikan skripsi tentu bukanlah hal yang mudah. Seringkali dalam penyelesaian skripsi mahasiswa mendapat berbagai hambatan atau masalah selama proses penyusunannya. Dari hasil studi pendahuluan yang dilakukan oleh peneliti pada beberapa mahasiswa Fakultas Keguruan dan Ilmu Pendidikan Universitas Halu Oleo Kendari, dalam proses penyusunan skripsi banyak mahasiswa yang memiliki beragam hambatan atau masalah. Masalah tersebut meliputi kesulitan dalam mencari literatur terkait penelitian, tuntutan-tuntutan dari luar yang membuat motivasi untuk mengerjakan skripsi menurun, kurangnya motivasi untuk mengerjakan skripsi, kesulitan bertemu dosen pembimbing, kurang memiliki pengetahuan tentang metodologi penelitian, revisian yang cukup banyak, minimnya kemampuan dalam tulis menulis yang dimiliki mahasiswa itu sendiri dalam tata cara penulisan skripsi, serta kesulitan untuk menemukan subjek penelitian.

Hasil wawancara tersebut didukung dengan studi terdahulu yang dilakukan oleh Wangid dan Sugiyanto (2013) bahwa masalah umum yang dihadapi oleh mahasiswa saat menyelesaikan skripsinya yaitu, kurang memiliki pengetahuan tentang metodologi penulisan skripsi, kebingungan dalam mengembangkan teori pendukung skripsi, dan sering mengalami hal-hal di luar skripsi yang mengganggu dalam penyusunan skripsi, kurang memiliki kemampuan dalam tulis menulis karya ilmiah, kesulitan dalam penyusunan pembahasan hasil penelitian, kurangnya buku-buku atau literatur yang terkait penelitian, kurang memiliki motivasi menyusun skripsi, kesulitan menemukan permasalahan yang ada, dosen pembimbing yang sibuk, sulit membagi waktu serta kesulitan dalam menyusun atau memahami kajian pustaka. Secara tidak langsung hambatan-hambatan tersebut akan menuntut mahasiswa untuk dapat menyesuaikan diri dan coping yang akan selalu dibutuhkan dalam setiap keadaan. Setiap individu mempunyai berbagai macam cara dalam mengatasi masalah atau hambatannya, baik mengatasi langsung permasalahan tersebut ataupun hanya menghadapi masalahnya dengan menenangkan emosinya. Cara-cara itulah yang disebut dengan coping.

Lazarus dan Folkman (dalam Putri dan Purba 2017) menyebutkan bahwa terdapat dua bentuk strategi coping yaitu (problem focused coping) dan (emotion focused coping). Secara umum, bentuk-bentuk coping yang berfokus pada emosi lebih mungkin terjadi ketika 
dinilai tidak ada yang dapat dilakukan untuk mengubah kondisi lingkungan yang berbahaya, mengancam atau menantang, sedangkan bentuk coping yang berfokus pada masalah lebih memungkinkan terjadi apabila kondisi lingkungan dinilai dapat diubah.

Menurut Mastuti (2010) problem focused coping adalah salah satu usaha untuk mengurangi tuntutan dari situasi yang tidak menyenangkan atau mengembangkan kemampuan untuk menghadapi sumbersumber masalah dan mengembangkan keterampilan-keterampilan yang baik dalam menghadapi suatu masalah, dari pada menghindari masalah-masalah tersebut. Lazarus dan Folkman (dalam Kadili 2018) menyebutkan bahwa problem focused coping lebih sering digunakan oleh individu dibandingkan emotion focused coping selama periode persiapan untuk ujian akademik. Problem focused coping merupakan strategi coping yang lebih baik dalam menghadapi masalah.

Smet (dalam Mastuti 2010) juga menjelaskan bahwa seseorang cenderung menggunakan pendekatan problem focused coping ketika mereka percaya bahwa sumber masalah atau situasi dapat diubah. Lazarus dan Folkman (dalam Prastuti dan Taufik 2014) menyatakan bahwa problem focused coping merupakan suatu proses dalam diri individu untuk mencoba mengelola jarak yang ada di antara tuntutan-tuntutan dengan sumber-sumber daya yang mereka gunakan dalam menghadapi situasi yang menekan. Problem focused coping juga dapat diartikan sebagai cara yang dilakukan individu dalam menghadapi masalah atau tuntutan-tuntutan yang berasal dari dalam diri maupun dari luar dengan berfokus pada pencarian pemecahan masalah hingga tuntas guna mengurangi tuntutan tersebut.

Strategi coping yang digunakan oleh individu dapat dipengaruhi oleh banyak faktor diantaranya stres, dukungan sosial, serta efikasi diri Lyrakos (2012). Peryataan ini didukung dengan hasil penelitian yang dilakukan oleh Rahmandani, Karyono, dan Dewi (2010) yang menyatakan bahwa faktor mempengaruhi strategi coping yaitu faktor eksternal yang yang menyangkut dukungan sosial, penguatan positif dan tekanan dari luar dan faktor internal yang menyangkut karakteristik kepribadian, sikap hati yang terbuka, serta isi kognitif. Isi kognitif salah satunya terdiri dari efikasi diri. Bandura (1995) menjelaskan bahwa efikasi diri adalah keyakinan individu mengenai kemampuan dirinya dalam melakukan tugas atau tindakan yang diperlukan untuk mencapai hasil tertentu.

Efikasi diri mengacu pada teori sosial kognitif Bandura (1997), yang menjelaskan bahwa peran efikasi diri sebagai mekanisme kognitif memunculkan fungsi kontrol individu dalam bereaksi terhadap stressor. Individu yang yakin dengan kemampuannya mengontrol stres secara efektif cenderung tidak gelisah. Sebaliknya jika individu tidak yakin akan fungsi kontrolnya menghadapi situasi yang tidak menyenangkan cenderung akan mengalami stres. Hal ini berarti bahwa efikasi diri berimplikasi pada kemampuan individu dalam menghadapi stressor. Efikasi diri akan ikut menentukan jenis coping yaitu seberapa keras usaha yang dilakukan individu untuk mengatasi persoalan atau menyelesaikan tugas, serta berapa lama individu mampu bertahan terhadap hambatan yang tidak diinginkan.

Bandura (1995) menjelaskan bahwa individu dengan efikasi diri tinggi akan menghubungkan kegagalan dengan usaha yang tidak cukup atau kurangnya pengetahuan. Efikasi diri yang tinggi akan mengembangkan kepribadian yang kuat pada diri individu sehingga seseorang tidak mudah terpengaruh pada situasi yang mengancam. Selanjutnya individu dengan efikasi diri yang rendah akan memandang buruknya prestasi sebagai akibat kelemahan kecerdasan otak yang tidak mungkin diperbaiki lagi. Pandangan yang pesimis ini membuat 
individu dengan efikasi diri yang rendah akan semakin kehilangan kepercayaan terhadap kapasitas dirinya, hal ini nantinya berakibat pada kesulitan saat menghadapi masalahmasalah yang ada. Dalam sesuatu yang sulit, individu dengan efikasi diri yang rendah cenderung akan mudah menyerah. Sementara itu individu dengan efikasi diri yang tinggi akan berusaha lebih keras untuk mengatasi tantangan yang ada. Begitu pula halnya dengan mahasiswa yang sedang menyusun skripsi, semakin tinggi efikasi diri yang dimiliki mahasiswa memungkinkan dirinya memiliki dorongan untuk melakukan usaha atau tindakan dalam menyusun skripsi, sebaliknya mahasiswa yang memiliki efikasi diri yang rendah maka kurang memiliki dorongan untuk melakukan usaha atau tindakan dalam menyusun skripsi.

Efikasi diri dalam hal ini akan mempengaruhi perilaku dan usaha mahasiswa ketika menghadapi masalah atau tuntutantuntutan dalam menyelesaikan skripsi hingga bisa mencapai hasil yang diinginkan. Hal ini berarti pada saat mahasiswa berhadapan dengan stressor, maupun usaha-usaha coping yang ditujukan akan bersumber pada efikasi diri yang diyakini mahasiswa. Apabila mahasiswa memiliki efikasi diri yang tinggi maka akan lebih mungkin bagi dirinya menggunakan problem focused coping untuk menangani tuntutan-tuntutan yang dialaminya. Sebaliknya apabila mahasiswa memiliki efikasi diri yang rendah akan menggunakan strategi coping yang dirasakan lebih mudah untuk dirinya. Hal ini dimungkinkan karena efikasi diri yang tinggi akan menuntut mahasiswa untuk bertahan terhadap situasi yang penuh tekanan serta tetap memiliki motivasi untuk bertindak dan berusaha untuk menyusun skripsi.

Tujuan dalam penelitian ini adalah untuk mengetahui hubungan antara efikasi diri dengan problem focused coping pada mahasiswa yang sedang menyusun skripsi di Fakultas Keguruan dan Ilmu Pendidikan Universitas Halu Oleo Kendari.
Penelitian ini diharapkan dapat mengembangkan informasi mengenai efikasi diri dengan problem focused coping, serta memberikan sumbangan ilmu pengetahuan terhadap perkembangan ilmu psikologi sehingga dapat menambah referensi ilmiah khususnya di bidang psikologi pendidikan dan psikologi klinis.

\section{Metode Penelitian}

Penelitian ini menggunakan jenis penelitian kuantitatif dengan teknik korelasional bermaksud untuk menganalisis data untuk mengetahui korelasi atau hubungan antara variabel satu dengan variabel yang lain, yaitu hubungan efikasi diri dengan problem focused coping. Hasil dari korelasi ini dapat menentukan hubungan positif atau hubungan negatif atau bahkan tidak menunjukkan korelasi antara variasi-variasi tersebut.

Populasi dalam penelitian ini adalah mahasiswa Fakultas Keguruan dan Ilmu Pendidikan Universitas Halu Oleo Kendari angkatan 2015 dengan jumlah mahasiswa sebanyak 1904 orang. Kriteria-kriteria dari populasi penelitian ini antara lain mahasiswa tingkat akhir Fakultas Keguruan dan Ilmu Pendidikan Universitas Halu Oleo Kendari, sedang mengerjakan tugas akhir atau skripsi, serta terdaftar aktif sebagai mahasiswa Universitas Halu Oleo Kendari.

Dalam penelitian ini, penentuan ukuran sampel menggunakan rumus Slovin, berdasarkan rumus Slovin diperoleh jumlah sampel yang akan dijadikan responden dalam penelitian ini sebanyak 95 mahasiswa Fakultas Keguruan dan Ilmu Pendidikan Universitas Halu Oleo Kendari. Jumlah anggota sampel bertingkat (berstrata) dilakukan dengan cara pengambilan sampel secara proportional random sampling yaitu menggunakan rumus alokasi proportional.

Pengambilan data digunakan dua skala, yaitu Skala efikasi diri dan skala problem focused coping. Metode penskalaan 
menggunakan format skala Likert 4 kategori jawaban, yaitu Sangat Setuju (SS), Setuju (S), Tidak Setuju (TS), dan Sangat Tidak Setuju (STS).

Skala efikasi diri mencakup 42 aitem yang disusun berdasarkan tiga aspek yaitu tingkat (magnitude), kekuatan (strength), generalisasi (generality) yang dikemukakan oleh (Bandura, 1977). Skala problem focused coping terdiri dari 33 aitem yang disusun berdasarkan aspek-aspek problem focused coping yang dikemukakan oleh Lazarus dan Folkman (Kadili, 2018) yaitu seeking informational support ((mencari dukungan informasi), confrontive coping (konfrontasi), dan planful problem solving (merencanakan pemecahan masalah).

Metode analisis statistik yang di gunakan untuk menganalisa data atau menguji hipotesis adalah model korelasional. Analisis data untuk mengungkap hasil penelitian menggunakan korelasi product moment milik Pearson dengan bantuan SPSS versi 16.0 for Windows untuk uji statistiknya.

\section{Hasil Penelitian dan Pembahasan}

\section{Tabel 1}

Hasil Uji Normalitas Efikasi Diri dan Problem Focused Coping One-Sample Kolmogorov-Smirnov Test

\begin{tabular}{lcc}
\hline & Signifikansi & Keterangan \\
\hline Efikasi Diri & 0,186 & $\begin{array}{l}\mathrm{P} \geq 0,05 \\
(\mathrm{Normal})\end{array}$ \\
\hline $\begin{array}{l}\text { Problem } \\
\text { Focused Coping }\end{array}$ & 0,355 & $\begin{array}{l}\mathrm{P} \geq 0,05 \\
\text { (Normal) }\end{array}$ \\
\hline
\end{tabular}

Uji normalitas dilakukan untuk mengetahui sebaran data yang diperoleh terdistribusi normal atau tidak. Kriteria suatu data dapat dikatakan memiliki distribusi normal jika memiliki taraf signifikansi (p) lebih besar dari 0,05 (p $\geq 0,05)$. Uji normalitas dilakukan dengan menggunakan teknik analisis Kolmogorov-Smirnov dalam program SPSS 16.0 for Windows.
Berdasarkan hasil uji normalitas diperoleh nilai signifikansi $p=0,186(p>0,05)$ untuk variable efikasi diri dan variable Problem focused coping diperoleh nilai signifikansi $\mathrm{p}=0,355(\mathrm{p}>0,05)$. Hasil tersebut menunjukkan bahwa variabel efikasi diri dan problem focused coping memiliki distribusi yang normal.

\section{Tabel 2}

Hasil Uji Linearitas Efikasi Diri dan Problem Focused Coping

\begin{tabular}{lccc}
\hline & & $\mathrm{F}$ & Signifikansi \\
\hline $\begin{array}{l}\text { Problem } \\
\text { Focused }\end{array}$ & (Combined) & 6.175 & .000 \\
\cline { 2 - 4 } Coping & Linearity & 225.485 & .000 \\
\hline $\begin{array}{l}\text { Efikasi } \\
\text { Diri }\end{array}$ & $\begin{array}{c}\text { Deviation } \\
\text { From } \\
\text { Linearity }\end{array}$ & .693 & .886 \\
\hline
\end{tabular}

Pengujian linieritas dimaksudkan untuk memperlihatkan bahwa rata-rata yang diperoleh dari kelompok data sampel terletak dalam garis-garis lurus. Uji linearitas dilakukan menggunakan test for linearity dengan bantuan program SPSS 16.0 for Windows. Kedua variabel dinyatakan linear jika memiliki nilai signifikansi lebih kecil dari $0,05(\mathrm{p} \leq 0,05)$.

Berdasarkan hasil uji linieritas menunjukkan bahwa variabel efikasi diri dan problem focused coping pada mahasiswa yang sedang menyusun skripsi memiliki nilai signifikansi $0,000(\mathrm{p} \leq 0,05)$. Hasil tersebut menunjukkan bahwa kedua variabel penelitian memiliki hubungan yang linier. 
Tabel 3

Hasil Uji Hipotesis Variabel Efikasi Diri dan Problem Focused Coping

\begin{tabular}{llcc}
\hline \multirow{2}{*}{$\begin{array}{l}\text { Efikasi } \\
\text { Diri }\end{array}$} & $\begin{array}{l}\text { Pearson } \\
\text { Diri }\end{array}$ & $\begin{array}{l}\text { Problem } \\
\text { Focused } \\
\text { Coping }\end{array}$ \\
\cline { 2 - 4 } & Correlation & 1 & $.858^{* *}$ \\
\cline { 2 - 4 } & Sig. (1-tailed) & & .000 \\
\hline $\begin{array}{l}\text { Problem } \\
\text { Focused }\end{array}$ & Pearson & 95 & 95 \\
\cline { 2 - 4 } Coping & Correlation & $.858^{* *}$ & 1 \\
\cline { 2 - 4 } & Sig. (1-tailed) & .000 & \\
\cline { 2 - 4 } & $\mathrm{N}$ & 95 & 95 \\
\hline
\end{tabular}

Uji hipotesis dalam penelitian ini menggunakan uji korelasi Product Moment Pearson dengan bantuan program SPSS 16.0 for Windows. Jika nilai signifikansi yang diperoleh lebih besar dari 0,05 ( $p \geq 0,05)$, maka hipotesis ditolak. Sebaliknya, jika nilai signifikansi yang diperoleh lebih kecil dari 0.05 ( $\mathrm{p} \leq 0.05)$, maka hipotesis diterima. Hipotesis dalam penelitian ini adalah terdapat hubungan positif antara efikasi diri dengan problem focused coping pada mahasiswa yang sedang menyusun skripsi.

Berdasarkan Tabel 3 dapat diketahui bahwa variabel efikasi diri berkorelasi positif dengan variabel problem focused coping pada mahasiswa yang sedang menyusun skripsi dengan koefisien korelasi sebesar 0,858 , dan nilai signifikansi sebesar 0,000 ( $\mathrm{p} \leq 0,05)$. Hal ini menunjukkan bahwa semakin tinggi efikasi diri mahasiswa maka semakin tinggi problem focused coping pada mahasiswa yang sedang menyusun skripsi. Sebaliknya, semakin rendah efikasi diri yang dimiliki maka semakin rendah problem focused coping pada mahasiswa yang sedang menyusun skripsi.

\section{Tabel 4}

Deskripsi Skor Efikasi Diri

\begin{tabular}{ccccc}
\hline $\begin{array}{c}\text { Sangat } \\
\text { Rendah }\end{array}$ & Rendah & Sedang & Tinggi & $\begin{array}{c}\text { Sangat } \\
\text { Tinggi }\end{array}$ \\
\hline 0 & 0 & 3 & 19 & 73 \\
\hline $0 \%$ & $0 \%$ & $2,3 \%$ & $20 \%$ & $76,8 \%$ \\
\hline
\end{tabular}

\section{Tabel 5}

Deskripsi Skor Problem Focused Coping

\begin{tabular}{ccccc}
\hline $\begin{array}{c}\text { Sangat } \\
\text { Rendah }\end{array}$ & Rendah & Sedang & Tinggi & $\begin{array}{c}\text { Sangat } \\
\text { Tinggi }\end{array}$ \\
\hline 0 & 1 & 5 & 24 & 65 \\
\hline $0 \%$ & $1,1 \%$ & $5,3 \%$ & $25,3 \%$ & $68,4 \%$ \\
\hline
\end{tabular}

Tabel 4 menunjukkan bahwa sebesar 76,8\% atau 73 subjek penelitian berada pada tingkat kategorisasi efikasi diri yang tinggi, sedangkan tabel 5 menunjukkan bahwa sebesar 68,4\% atau 65 subjek penelitian memiliki problem focused coping yang tinggi. Hal ini menunjukkan bahwa saat penelitian berlangsung, mayoritas subjek penelitian memiliki problem focused coping yang tinggi dan efikasi diri yang tinggi.

Faktor-faktor yang mempengaruhi tingkat efikasi diri subjek berkategori sangat tinggi disebabkan karena subjek memiliki kepercayaan diri yang tinggi dalam menghadapi masalah skripsi, memiliki keyakinan yang tinggi untuk menyelesaikan tugas-tugas skripsi, berusaha mencari jalan keluar atau strategi dalam menghadapi masalah, misalnya tetap berusaha mencari referensi buku dengan sabar, berdoa, tidak mudah menyerah dan lain sebagainya (Mastuti, 2010).

Ulfah (2010) juga menjelaskan bahwa mahasiswa yang memiliki efikasi diri yang tinggi akan memotivasi diri secara kognitif untuk bertindak lebih tepat dan terarah, terutama apabila tujuan yang hendak dicapai merupakan tujuan yang jelas.

Skor problem focused coping yang tinggi pada subjek tersebut menunjukkan 
bahwa subjek memiliki cara untuk mencari bantuan berupa saran mengenai masalah skripsi, melakukan usaha untuk memecahkan masalah skripsi serta mencari solusi terhadap masalah yang dihadapi.

Penelitian Shimazu dan Wilman (2007), juga menjelaskan bahwa individu yang memiliki problem focused coping positif akan dapat mengelola emosi dalam menyelesaikan tuntutan kerja yang menekannya sehingga stress kerja dalam lingkungan kerja dapat berkurang.

Penelitian Chu dan Chao (2011), juga menjelaskan bahwa problem focused coping memiliki manfaat untuk membantu mempertahakan kesejahteraan seseorang dan membantu seseorang terhindar dari tuntutan lingkungan yang menekannya. Didukung dengan penelitian Semaraputi dan Rustika (2018) bahwa individu dengan problem focused coping yang tinggi akan berusaha untuk membuat kondisi masalah yang dihadapi kembali stabil dengan cara introspeksi diri, setelah memahami masalah dan berusaha untuk menstabilkan kondisi diri, individu dengan problem focused coping tinggi akan melakukan analisis untuk melakukan pemecahan masalah dalam mengatasi kondisi stres, memahami masalah, serta membuat perencanaan perilaku sebagai solusi untuk mengatasi masalah.

Hasil analisis data menunjukkan koefisien korelasi sebesar 0,858 dan dapat diketahui koefisien determinasi atau besar hubungan antara variabel satu dengan variabel yang lain (r2) yaitu 0,736 artinya pengaruh efikasi diri dengan problem focus coping adalah sebesar $73,6 \%$. Selebihnya $26,4 \%$ dipengaruhi oleh faktor-faktor lain diluar efikasi diri. Faktor-faktor tersebut diantaranya optimisme, pesimisme, kesehatan mental (Rezaei et al, 2015). Stres, dukungan sosial (Lyrakos, 2012) dan lain-lain.

\section{Kesimpulan dan Saran}

\section{Kesimpulan}

Berdasarkan tujuan penelitian dan hasil penelitian yang dilakukan pada 95 mahasiswa di Fakultas Keguruan dan Ilmu Pendidikan Universitas Halu Oleo Kendari Provinsi Sulawesi Tenggara dapat disimpulkan sebagai berikut:

1. Terdapat hubungan positif antara efikasi diri dengan problem focused coping pada mahasiswa yang sedang menyusun skripsi di Fakultas Keguruan dan Ilmu Pendidikan Universitas Halu Oleo Kendari. Hasil penelitian ini sesuai dengan hipotesis yang diajukan oleh peneliti, yaitu terdapat hubungan positif antara efikasi diri dengan problem focused coping pada mahasiswa yang sedang menyusun skripsi. Semakin tinggi efikasi diri maka semakin tinggi problem focused coping pada mahasiswa yang sedang menyusun skripsi, sebaliknya semakin rendah efikasi diri maka semakin rendah pula problem focused coping pada mahasiswa yang yang sedang menyusun skripsi. Sehingga hipotesis yang diajukan oleh peneliti diterima.

2. Mahasiswa yang sedang menyusun skripsi di Fakultas Keguruan dan Ilmu Pendidikan Universitas Halu Oleo Kendari memiliki efikasi diri dan problem focused coping yang tergolong tinggi.

3. Sumbangan efektif atau peranan efikasi diri terhadap problem focused coping pada mahasiswa yang menyusun skripsi di Fakultas Keguruan dan Ilmu Pendidikan Universitas Halu Oleo Kendari yaitu sebesar (r2) 73, 6\%. Selebihnya 26, 4\% dipengaruhi oleh faktor-faktor lain yang berpengaruh terhadap strategi coping di luar faktor efikasi diri. 


\section{Saran}

\section{Bagi Mahasiswa}

Bagi mahasiswa tingkat akhir diharapkan dapat mengembangkan efikasi diri yang dimiliki sehingga mampu memikirkan cara yang terbaik dan menentukan langkah-langkah untuk mengatasi kesulitan dalam menyusun skripsi. Untuk mengembangkan efikasi diri dapat dilakukan dengan cara mengikuti seminar motivasi, berkonsultasi dengan dosen pembimbing, berani menghadapi tantangan, membuat timeline, mencari lebih banyak referensi, dan mempersiapkan diri pada ujian skripsi.

\section{Bagi Fakultas atau Program Studi}

Pihak fakultas diharapkan membuat rancangan program berupa kegiatan pengembangan efikasi diri sehingga membantu mahasiswa untuk mampu mengembangkan cara-cara yang efektif dalam menghadapi suatu permasalahan akademik.

\section{Bagi Peneliti Selanjutnya}

Bagi peneliti selanjutnya untuk memperhatikan dalam teknik pengambilan data agar mempermudah dalam pengambilan data. Selain itu untuk meningkatkan kualitas penelitian lebih lanjut khususnya yang berkaitan dengan efikasi diri dengan strategi coping pada mahasiswa yang menyusun skripsi, disarankan menyempurnakan hasil penelitian ini dengan cara memperbanyak jumlah subjek penelitian serta menggunakan variabel lain yang belum diungkap dalam penelitian ini.

\section{Daftar Pustaka}

Bandura, A. (1997). Self-Efficacy: The exercise of control. New York: W.H. Freeman and Company.

Bandura, A. (1995). Self-Efficacy in changing societies. New York: Cambridge University Press.
Chu, R., \& Chao, L. (2011). Managing stress and maintaining well-being: Social support problem-focused coping, and avoidant coping. Journal of Counseling and Development,89(3).

Kadili, N. D. (2018). Kecerdasan emosional dan problem focused coping pada mahasiswa yang sedang menyusun skripsi. Skripsi. Universitas Sanata Dharma, Yogyakarta.

Lyrakos, D. G., (2013). The impact of stress, social support, self-efficacy and coping on University Students, a Multicultural European Study. Psychology, 3(2), 143-149.

Mastuti, N. P. (2010). Hubungan efikasi diri dengan problem focus coping dalam menyusun skripsi pada mahasiswa psikologi. Skripsi. Universitas Islam Negeri Sultan Syarif Kasim, Riau.

Prastuti, A. P., \& Taufik. (2014). Hubungan antara kecerdasan emosi dan problem focus coping dengan perilaku delinkuen pada siswa smp. Jurnal Penelitian Humaniora, 15(1), 15-23.

Putri, A. N., \& Purba, D. E. (2017). The mediating effect of problem-focused coping on the relationship between job insecurity and impression management. Advances in Social Science, Education and Humanities Research,139, 271-276.

Rahmandani, A., Karyono., \& Dewi, E. A. (2010). Strategi penanggulangan (coping) pada ibu yang mengalami postpartum blues di rumah sakit umum daerah kota semarang. Universitas Diponegoro, Semarang.

Rezaei, S. G., Mousavi, S. S., Safari, F., Bahrami, H., \& Menshadi, S. M. (2015). Study of relationship 
between optimism, pessimism and coping strategies with mental health among University Students of Lorestan. Open Journal of Social Sciences, 3, 190-195.

Semaraputri, S. A. \& Rustika, I. M. (2018). Peran problem focused coping dan konsep diri terhadap penyesuaian diri pada remaja akhir yang menjadi pengurus organisasi kemahasiswaan di fakultas kedokteran universitas udayana. Jurnal Psikologi Udayana. 5(1), 35-47.

Shimazu, A. \& Schaufeli, W. B. (2007). Does distraction facilitate problem focused coping with job Stress? A 1 year longitudinal study. Journal of Psychology, 30, 423-434. DOI10.1007/s10865-007-9109-4.

Suwarsi, S., \& Handayani, A. (2017). Hubungan antara optimisme dan problem focused coping pada mahasiswa yang sedang menyusun skripsi. Proyeksi, 12(1), 35-44.

Ulfah, S. H. (2010). Efikasi diri mahasiswa yang bekerja pada saat penyusunan skripsi. Skripsi. Universitas Muhammadiyah. Surakarta.

Wangid, M. N., \& Sugiyanto. (2013). Identifikasi hambatan struktural dan kultural mahasiswa dalam menyelesaikan tugas akhir. Jurnal Penelitian Ilmu Pendidikan, 6(2), 1928. 